\title{
A IMPORTÂNCIA DA EDUCAÇÃO AMBIENTAL LÚDICA: ABORDAGENS E REFLEXÕES PARA A CONSTRUÇÃO DO CONHECIMENTO INFANTIL
}

Vanessa Oliveira Fernandes Câmara ${ }^{1}$

RESUMO: Modelos educacionais ocidentais frequentemente desconsideram a vertente emocional dos conteúdos curriculares, sem reconhecer o seu devido valor como parte importante deste complexo contexto. Tais modelos precisam ser renovados para atender às demandas da sustentabilidade, estabelecendo uma nova relação entre criança e natureza. Neste sentido, esse estudo objetiva compreender como as atividades lúdicas inseridas em ações educativas trazem benefícios à educação ambiental e consequentemente à manutenção de ecossistemas ameaçados. Foram utilizados a revisão bibliográfica e análise documental como técnicas de pesquisa. Os resultados evidenciaram que através de estratégias lúdicas que provocam emoções é possível construir uma relação saudável entre os seres humanos e os outros seres vivos, auxiliando o processo de formação do sujeito ecológico.

Palavras-chave: Educação ambiental, Ludicidade, Infância.

${ }^{1}$ Mestre em Desenvolvimento e Meio Ambiente - Universidade Federal da Paraíba, Gerente Executiva de Meio Ambiente da Secretaria Executiva de Meio Ambiente da Paraíba. 


\section{Introdução}

Em meados do Século XX surgiam as discussões acerca da crise ambiental que ainda hoje inquieta o planeta. Logo, os assuntos ambientais tornaram-se temas de diversos debates e grande interesse na vida social mundial. A Educação Ambiental (EA) foi sempre aparecendo nos diversos espaços de discussão dirigidos a temáticas ambientais como um dos instrumentos relevantes na busca de respostas para a crise. Nesse contexto, o presente estudo se propõe a contribuir com reflexões acerca da importância da ludicidade para a educação ambiental infantil, em especial a EA não formal, considerando variadas maneiras de realização de ações educativas voltadas para a sensibilização ambiental em diferentes espaços. Assim, tem como objetivo geral o debate acerca das interações e aprendizagem que podem ser resignificadas a partir de estratégias educativas mais lúdicas a serem utilizadas na EA. Constitui parte da fundamentação teórica da pesquisa de mestrado intitulada "Teatro de bonecos como ferramenta de sensibilização ambiental em unidades de conservação" realizada através do Programa de Pós Graduação em Desenvolvimento e Meio Ambiente - PRODEMA na Universidade Federal da Paraíba, registrado e autorizado pelo Comitê de ética e pesquisa sob o $\mathrm{n}^{\circ}$ Caae: 54265916.6.00005188.

Grandes eventos sob a égide da Organização das Nações Unidas (ONU) vinham apresentando princípios e práticas a respeito e não se nega que este surto de novas diretrizes ambientais deveu-se à grande provocação da Conferência sobre o meio ambiente, realizada em Estocolmo, em junho de 1972. Esse foi um dos eventos de maior repercussão em toda a história após a $2^{\circ}$ guerra mundial, propulsor de inúmeros desdobramentos e práticas voltadas para uma nova consciência ecológica e a convivência humana com o planeta.

Logo após, no Brasil, houve a ECO 92, realizada no Rio de Janeiro em 1992 tendo produzido grande fruto, a Agenda 21 Global, dando ênfase em seu capítulo 36 à Educação Ambiental, daí por diante, o debate alastrou-se e intensificou-se. Embora a Constituição Federal de 1988 em seu art. 225, § 1ํ, $\mathrm{VI}$, já estabelecesse a obrigação do Poder Público de "promover a EA em todos os níveis de ensino e a conscientização pública para a preservação do meio ambiente". Bem como a Política Nacional de Meio Ambiente ${ }^{2}$ instituída em 1981 que prevê a "educação ambiental a todos os níveis de ensino, inclusive a educação da comunidade, objetivando capacitá-la para participação ativa na defesa do meio ambiente" como um princípio da política citada. Logo, observase que o contexto estava muito bem preparado para a chegada da Política Nacional de Educação Ambiental (PNEA).

Consagrada na legislação pátria através da Lei Federal n 9.795 de 1999 a Política Nacional de Educação Ambiental compreende a Educação Ambiental (EA) como:

\footnotetext{
${ }^{2}$ Lei $n^{\circ} 6.938 / 1981$ (PNMA)
}

revista brasileira educação ambiental 
Os diversos processos por meio dos quais o indivíduo e a coletividade constroem valores sociais, conhecimentos, habilidades, atitudes e competências voltadas para a conservação do meio ambiente, bem de uso comum do povo, essencial à sadia qualidade de vida e sua sustentabilidade (Art. $1^{\circ}$ da Lei 9.795/1999).

A referida lei, considerada de maior relevância educacional, definindo a natureza da EA, seus princípios básicos e objetivos foi resultado de um processo evolutivo de movimentos e mudanças ocorridas no mundo inteiro desde meados do século $X X$, as inúmeras conferências e relatórios fortaleceram as discussões em torno da crise ambiental também no Brasil (MACHADO, 2014).

Em todo o texto legal da PNEA, a EA é voltada para propostas pedagógicas centradas na conscientização, mudança de comportamento, desenvolvimento de competências, capacidade de avaliação e participação dos educandos. Também observa que deve propiciar o aumento de conhecimentos, mudanças de valores e aperfeiçoamento de habilidades, condições básicas para estimular uma maior integração e harmonia dos indivíduos com o meio ambiente.

Carvalho (2011) explicou que a expressão "Educação Ambiental" vem sendo utilizada como um termo bem genérico para algo que se aproxima de tudo o que pode ser acolhido sob o guarda-chuva das "boas práticas ambientais". É possível observar variados conceitos de EA, contudo a maioria deles apresenta a EA como um processo ${ }^{3}$, significando que a educação ambiental em si constitui uma construção de uma consciência global das questões relativas ao ambiente (SATO, 1997; SAUVÉ, 2005; REIGOTA, 2010; BARCELOS, 2012; DIAS, 2014).

Entre as diversas vertentes que se apresentam nas discussões conceituais sobre EA, verifica-se a sua crescente valorização como uma ação educativa que deveria estar presente, de forma transversal e interdisciplinar, articulando o conjunto de saberes, formação de atitudes e sensibilidades ambientais (CARVALHO, 2011).

Nesse contexto, esse estudo não pretende discutir a diversidade conceitual da EA, apenas partilhar a postura teórica de Sato (1995) e Carvalho (2011). A primeira percebe a EA como uma educação que dialoga com o ambiente do qual emerge, considerando as demandas socioambientais e as características que cada cultura possui, abrindo caminho para uma educação dinâmica, crítica e transformadora. E a segunda aponta para o estabelecimento de um amplo conjunto de práticas sociais voltadas para os

\footnotetext{
3 Processo: Ato de proceder ou de andar. Sucessão sistemática de mudanças numa direção definida. Concatenação ou sucessão de fenômenos. Seguimento, decurso. Série de ações sistemáticas visando a certo resultado. Ação ou operação contínua ou série de ações ou alterações que ocorrem de uma maneira determinada. Ação de ser feito progressivamente (HOUAISS, 2009).
}

Revbea, São Paulo, V. 12, № 4: 60-75, 2017. 
diferentes aspectos das relações entre sociedade e ambiente, constituindo assim o que a autora chama de Campo Ambiental ${ }^{4}$.

Enquanto ação educativa, a EA tem sido importante mediadora entre a esfera educacional e o campo ambiental, dialogando com novas dificuldades geradas pela crise ecológica produzindo reflexões, concepções, métodos e experiências que visam construir novas bases de conhecimentos e valores ecológicos nesta e nas futuras gerações.

Nesse sentido, educar ambientalmente significa, além da apropriação de conceitos e processos relacionados com o ambiente, a aquisição de visões de mundo que possibilitem o respeito a todas as formas de vida, bem como o entendimento de que a vida só se dá pelas complexas teias tecidas pelos elementos naturais e socioculturais que se entrelaçam (CAPRA, 2006).

A meta não é o simples conhecimento de matérias específicas, mas estabelecer ligações entre a cabeça, mão, o coração e a capacidade de reconhecer os diferentes sistemas e tudo o que os interliga. À luz de Capra (2006), para ser ecologicamente alfabetizada uma pessoa precisa ter no mínimo conhecimentos básicos de ecologia, ecologia humana e dos conhecimentos de sustentabilidade, bem como dos meios necessários para a solução dos problemas.

Nesse amplo diálogo que não se objetiva aqui esgotar, resgata-se a importância de uma EA relacionada com questões humanas atemporais, voltada para uma educação sensibilizadora e afetiva que possa ampliar as percepções de mundo.

Então, é possível entender que a EA tem um papel integrador, integra disciplinas, saberes, ensinamentos, aprendizados, práticas. Sob o ponto de vista pedagógico e educacional, ela contribui para dar unidade e convergência aos diferentes tratamentos que se encontram nos sistemas educacionais. Sob a ótica do educando, ela o insere em relações bem ordenadas com o mundo natural e o meio social, demostrando sentido de solidariedade e reduzindo-lhe as atitudes individualistas. Esse conjunto é o terreno fértil para ver surgir o sujeito ecológico. Carvalho (2011, p.98) explica que a "formação de uma atitude ecológica pode ser considerada um dos objetivos mais perseguidos e reafirmados pela EA crítica". Essa atitude é definida pela autora como "a adoção de um sistema de crenças, valores e sensibilidades éticas e estéticas orientado segundo os ideais de vida de um sujeito ecológico ${ }^{5}$.

Contudo, é preciso notar que a EA, mesmo através dos melhores métodos e procedimentos, não pode remediar todos os males e deficiências

\footnotetext{
${ }^{4}$ Segundo Carvalho (2011,p.75), compõem esse campo ambiental as ações de governo e da sociedade civil, a produção editorial de livros sobre meio ambiente e a formação de especialistas, configurando uma área de conhecimentos e de profissionalização com características próprias. Ressaltando que o educadores ambientais complementam esse campo e nele representam um dos novos tipos de profissionais ambientais.
}

${ }^{5}$ Op cit (p. 177)

Revbea, São Paulo, V. 12, № 4: 60-75, 2017.

revista brasileira educação ambiental 
que se encontram na sociedade, mas entende-se que a EA é um impulso dinâmico no longo processo de educação para a cidadania e formação de sujeitos ecológicos, impulso que sempre se renova porque a questão ambiental apresenta continuamente novas indagações.

Dessa maneira, tais impulsos podem chegar aos sujeitos de diversas formas, seja sob a ótica da educação formal ou não formal conforme preconiza a Política Nacional de EA.

\section{Tipos de EA}

A EA aqui é considerada como uma atividade-fim, visto que ela se destina a formar a consciência ecológica para o exercício de uma cidadania solidária com todas as formas de vida. Configurando-se como um instrumento valioso na geração de atitudes, hábitos e comportamentos que concorrem para garantir o respeito ao equilíbrio ecológico e à qualidade do ambiente como patrimônio da coletividade.

A EA tem seus horizontes amplamente abertos comportando seu exame sob dois aspectos legais: o formal e o não formal.

Sob o aspecto formal, a EA refere-se ao ensino programado das escolas, seja no ensino privado ou público e em todos os graus, educação básica - educação infantil, ensino fundamental e médio; educação superior; educação especial; educação profissional e de jovens e adultos (art. 9 da PNEA). O texto legal ainda ressalta que a prática educativa deve ser integrada, contínua e permanente em todos os níveis do ensino formal, vedando a possibilidade de implantação de disciplinas específicas no currículo do ensino, exceto nos cursos de pós-graduação e extensão (art. 10).

Associados a isso, surgem os Parâmetros Curriculares Nacionais (PCN), publicados para que cada escola adapte seu currículo à realidade local e faixa etária dos estudantes. Os $\mathrm{PCNs}^{6}$ apresentam o meio ambiente como um dos temas transversais na educação formal, indicando que se permeiam os conteúdos e orientações didáticas em todas as disciplinas, no período de escolaridade obrigatória (MEC, 1997).

Sob o aspecto não formal, a EA refere-se às "ações e práticas educativas voltadas à sensibilização da coletividade sobre as questões ambientais e à sua organização e participação na defesa da qualidade do meio ambiente"7 fora do espaço escolar.

Essa modalidade tem grande aplicabilidade na educação popular, contribuindo para aperfeiçoar a consciência dos problemas ambientais e para buscar soluções práticas para eles a partir de reflexões e debates dentro da própria comunidade em que o sujeito está inserido. A EA não formal tem sido

${ }^{6}$ Ministério da Educação. Parâmetros Curriculares Nacionais. Brasília - DF, 1997

Disponível em: http://portal.mec.gov.br/component/content/article?id=12598:publicacoes

7 Art. 13 da lei $n^{\circ} 9.795 / 1999$ - PNEA

Revbea, São Paulo, V. 12, No 4: 60-75, 2017. 
incentivada pela UNESCO${ }^{8}$ e reconhecida como educação permanente e como fator de desenvolvimento humano continuado. Milaré (2013) ensina que qualquer espaço pode ser utilizado para ações educativas, bem como os mais diversos grupos da sociedade podem e devem desenvolver tais ações.

De maneira não formal, é possível utilizar casas de cultura, associações civis, entidades profissionais, unidades de conservação, igrejas, praças para realizações de atividade de educação ambiental, constituindo-se uma excelente oportunidade para sensibilizar e formar sujeitos ecológicos.

Assim o aspecto utilizado neste estudo é o não formal, utilizando ferramentas lúdicas voltadas para o público infantil.

\section{Educação infantil - o que significa ensinar crianças?}

Quando se fala em "educação infantil", facilmente associa-se o termo à primeira etapa da Educação básica do ensino formal, regido e regulamentado por vasto arcabouço legal em nosso país, em especial a Lei $n^{\circ}$ 9.394 de 1996 e suas mais recentes alterações ${ }^{9}$ que estabelecem as diretrizes e bases da educação nacional. A educação infantil brasileira passa por debates e movimentações importantes. No atual cenário, o papel políticopedagógico modificou-se bastante, retratando novos parâmetros de definição das políticas públicas, de implementação de projetos pedagógicos nas instituições de ensino e outras, que fazem a educação não formal (FREIRE,2003)

Para tanto, o objetivo dessa discussão não consiste nas prerrogativas da educação infantil no âmbito do ensino formal, mas sim sob o debate da importância de investir esforços para aguçar o pensamento infantil, principalmente um pensamento crítico em relação ao ambiente em que se vive.

Capra (2006) observa a urgência na expansão da educação infantil, ressaltando a necessidade de maiores orientações com relação às experiências práticas, que, além de desenvolverem contextos diversos da realidade, reincidem em erros já bem conhecidos, como a não observação da criança enquanto sujeito histórico e de direitos repleto de habilidades potenciais.

O mundo infantil possui muitas nuances, diferentes abordagens teóricas que versam sobre seu psiquismo, sua linguagem, seu desenvolvimento físico, emocional e motor. O desenvolvimento cognitivo de uma criança passa por diversas etapas, que acontecem em consonância com o seu desenvolvimento global, isto é, o motor, o psicológico e o intelectual (PIAGET,1995, p. 67).

\footnotetext{
8 Disponível em: http://www.unesco.org/new/pt/brasilia/

9 Em 2013, 2014 e 2015 a referida Lei passou por diversas alterações e complementações textuais através das leis: Lei no 12.796/ 2013; Lei no 13.006/2014; Lei no⒔234/2015
}

revista brasileira educação ambiental 
A criança age com muita liberdade ao brincar e se comunicar, o que não acontece bem na fase adulta. Sendo assim, Piaget $(1995$, p. 85$)$ reconhece as transformações na construção do conhecimento, estas bastante significativas no decorrer das idades de dois a dez anos.

Os conhecimentos da criança são efetivamente construídos, mas não podem ser reduzidos a uma reprodução interna de tudo o que o meio oferece. As trocas linguísticas, a possibilidade de acesso à cultura, às informações, os intercâmbios sociais, a oportunidade de experiências diversas são aspectos decisivos nos ritmos desse desenvolvimento infantil (VYGOTSKY, 2006, p. 183).

A criança é um ser social, o que significa dizer que o seu desenvolvimento dá-se entre outros seres humanos. É na interação social que se estabelecem contatos e se utilizam instrumentos mediadores. A vivência no meio, com atividade instrumental e interação com outros indivíduos permitirá o desenvolvimento de um novo e complexo sistema psicológico (VYGOTSKY, 2005).

Morin (2012) também apresenta a complexidade da formação de conhecimentos necessários à contemporaneidade, bem como a proposta de superação da visão linear da educação tradicional. Nos moldes atuais das civilizações, não se trata de estratégias educativas voltadas para campos específicos, mas superar essa visão remete à tentativa mais abrangente de articular os vários tipos de conhecimentos, sem, no entanto, procurar encerrar as impressões e contextos de mundo numa racionalização.

Nesse sentido, ensinar (educar) crianças consiste na busca de um paradigma sistêmico e complexo na educação infantil, exigindo mudanças nos processos de aprendizagem em todos os níveis. Logo, urge ultrapassar 0 paradigma conservador que vem caracterizando práticas baseadas na transmissão e repetição de informações (HORTON, 2007; MORIN, 2012).

Nesse ponto, faz-se importante observar com atenção para a pedagogia que de fato se pratica nas instituições onde as crianças cada vez mais passam parte significativa de suas infâncias. O que se verifica, e que isso não é apenas no Brasil, é que onde a pedagogia, enquanto reflexão crítica e atualizada sobre as práticas educativas, encontram-se ausentes ou mal-entendidas, a pedagogia tradicional - aquela que somente percebe o aluno e não a criança na figura do educando, é que ocupa seu lugar de sempre.

Para rematar, Dewey (2007, p. 47) lembra que o "debate entre criança e o currículo não deve levar à exclusão nem da criança, dos seus interesses e motivações, nem do currículo, no que ele representa de significados, objetivos e valores sociais". No caso da educação infantil, o autor também observa a necessidade de uma pedagogia que promova o respeito à criança e a suas condições de aprendizagem. 


\section{Aprendizagem infantil}

Em uma breve análise, a palavra "infância" é utilizada como um substantivo que indica uma etapa do desenvolvimento humano que vai desde 0 nascimento à puberdade e à adolescência ou também é usada como um adjetivo que caracteriza um estado de ingenuidade ou de simplicidade que independe do período cronológico. Esse duplo sentido, atribuído à noção de infância em diversas línguas encontra-se interrelacionado e articulado com a origem etimológica da palavra infantia, proveniente do latim: do verbo fari, falar - especificamente, de seu particípio presente fan, falante - e de sua negação in. O infans é aquele que, como diz Gagnebin (1997 p. 87), ainda não adquiriu "o meio de expressão próprio de sua espécie: a linguagem articulada". O prefixo in da palavra "infância" sugere ainda algo da ordem do não exprimível, do não tratável discursivamente, mais do que uma ausência, é uma condição dessa linguagem e desse discurso, é o germe do pensamento que ainda não se encontra pronto nem acabado, que ainda não se pode expressar ou comunicar em termos lógicos, linguísticos ou pragmáticos (HOUAISS, 2009; AURÉLIO, 2010). Assim, em sua origem etimológica, percebe-se que a infância consiste no silêncio que precede a emissão das palavras e a enunciação do discurso, designando uma condição da linguagem e do pensamento com a qual o ser humano se defronta ao longo de sua vida, mas, com maior frequência, em uma idade específica, diferenciada da adulta, na qual ainda não adentrou no mundo público.

A noção de infância conhecida atualmente é produto da evolução da história humana, sendo transformada de acordo com cada sociedade nas organizações e estruturas econômicas e sociais do momento. Os processos de aprendizagem das crianças têm seu início ainda no ventre materno, segundo Agamben (2005) "não é só o corpo que se forma durante a gravidez. A personalidade, a inteligência e os traumas também estão em gestão".

A criança interage com uma educação infantil na barriga da mãe. É preciso estímulos para a boa formação dos neurônios. As diversas sensibilidades formam-se dentro do útero, desde a sensibilidade musical até a habilidade linguística adquirida no final da gestação (PIAGET, 2012). Assim, não há dúvida que muito se aprende no ventre materno. No início da educação infantil, naturalmente, a aprendizagem é por imitação do que é visto e vivenciado no cotidiano. Santos $(2006$, p. 34) lembra que "as crianças são como esponjas, absorvem tudo o que fazemos, tudo o que dizemos. Aprendem conosco o tempo todo, mesmo quando não nos damos conta de que estamos ensinando".

As mais diversas teorias de aprendizagem buscam reconhecer a dinâmica envolvida nos atos de ensinar e aprender, partindo do reconhecimento da evolução cognitiva do ser humano, e tentam explicar a relação entre o conhecimento novo e o preexistente. As aprendizagens não perpassam apenas pela construção do conhecimento, mas também pela identificação pessoal e a relação que se dá através da interação entre as pessoas.

revista brasileira educação ambiental 
À luz de Antunes (2012), o desafio é ainda maior, pois sabe-se que a aprendizagem está intrinsecamente relacionada com a forma, e como o indivíduo interage com 0 meio em que está inserido na sociedade. As aprendizagens evoluem, então, num ambiente pedagógico em que há respeito à livre iniciativa e há busca de equilíbrio entre liberdades individuais e direcionamentos coletivos existe um "desabrochar" de capacidades inatas das crianças.

Nesse contexto, Gagnebin (1997) explica que no desenvolvimento cognitivo infantil, intervém um conteúdo biológico, sem o qual nada seria possível, se não houver um organismo dotado de estruturas orgânicas e funcionando de modo integrado, não há possibilidades de os conhecimentos progredirem. Ocorre também a forte influência do meio social adulto, das experiências e do que, a partir delas, a criança pode internalizar ou abstrair das transmissões educativas e dos fatores ligados ao funcionamento intelectual. Piaget (2012) conclui que durante a evolução da aprendizagem, a criança reelabora a seu modo o que lhe é transmitido e extrai de suas experiências aquilo que seu nível de entendimento possibilita.

A aprendizagem verdadeira dá-se no exercício operacional da inteligência. Em sentido estrito, a aprendizagem refere-se às aquisições relacionadas com informações e dá-se no decorrer do desenvolvimento (VIGOTSKI, 2005). A inteligência é o instrumento de aprendizagem mais necessário. $O$ ensino, nessa abordagem, deve estar baseado em proposições de problemas e soluções.

Para que a criança, partindo da hipótese de que a aprendizagem da leitura e escrita, por exemplo, não se limite à sala de aula, é necessário que ela assimile, selecione, processe, interprete e faça relações com as atividades e conteúdos. Dessa maneira, é possível entender que para aprender a criança necessita realizar um importante trabalho cognitivo, construindo representações dos mesmos e atribuindo significados. O tempo e a condição de aprender da criança requerem criações e aprendizagem interativas e dinâmicas.

\section{Interações e aprendizagens na perspectiva da EA construtivista}

Educadores que trabalham visando a aprendizagem significativa dos conteúdos devem estar atentos ao fato de que a criança tem algo a dizer, pensa algo, vê sob uma perspectiva o fato, o fenômeno e qualquer conteúdo passível de aprendizagem.

Desconsiderar tais atenções, é, de certa forma, aceitar que apenas o educador sabe de tudo e, portanto, é o único capaz de ensinar sobre o mundo. Educadores que pensam dessa maneira costumam adotar um modelo de ensino-aprendizagem por transmissão-recepção em seus ambientes de aprendizagem. Logo, essa forma de estratégia de ensino não considera as orientações construtivistas, estando mais próxima de ideias de uma educação tradicional conservadora.

Revbea, São Paulo, V. 12, № 4: 60-75, 2017. 
É comum educadores que planejam ações didáticas apenas preocupados com o que dizer e expor às crianças, bem como aquilo que esperam que elas digam durante uma ação/aula. Muitos não imaginam e nem consideram que as crianças são capazes de dizer ou fazer por si mesmas. Concentram-se nas próprias ideias sobre o assunto/conteúdo e não no modo como as crianças os compreendem e internalizam as informações.

Ao desconsiderar o que as crianças têm a dizer, o educador ignora uma tendência moderna para a didática das ciências da natureza. Ou seja, se o objetivo é promover uma aprendizagem significativa, e não baseada puramente na memorização do conteúdo, não se pode ignorar alguns pontos básicos, como:

- É de grande importância aquilo que a criança já sabe ou pensa a respeito de determinado assunto/tema;

- Encontrar um sentido supõe estabelecer relações: o que está na memória não são fatos isolados, mas aqueles que guardam relações com os outros em nossa mente;

- Quem aprende constrói significados;

- Os estudantes também são responsáveis pela própria aprendizagem.

Nesse contexto, admite-se que a aprendizagem não se dá apenas pela memorização, mas pela intensa atividade mental do educando. Cabendo o uso de atividades e ações que permitam às crianças fazer relações e atribuir significados àquilo com que toma contato nas situações de ensinoaprendizagem. Atividades que ofereçam oportunidades de desenvolver suas ideias e seus conceitos dos elementos ambientais devem ser utilizadas.

Dessa maneira, observa-se que 0 ensino tradicional se mostra ineficiente quando se começa a dar prioridade ao ensino do "método científico" e assim deve adequar uma nova maneira de ensinar ciências ambientais, o "ensino por descoberta", este tenta aproximar os estudantes das atividades científicas e da própria história das ciências. Essa nova forma de ensinar é baseada na ideia das crianças vivenciarem o método científico. Acredita-se que por meio de observações, experimentos, atividades práticas e lúdicas, vivências in loco proporcionam um maior envolvimento da criança com o conteúdo explorado (PEREIRA, 2003).

Capra (2006) chamou a atenção para inserir na aprendizagem infantil elementos como admiração, descoberta, interpretação, destreza e surpresa, bem como pôr em prática a crença de que todo o mundo tem talentos artísticos, mesmo não sendo artista. O autor afirma "que as crianças compreendem e se recordam melhor dos conceitos quando elas aprendem pela experiência pessoal direta" (p. 123).

Antunes (2012) reitera que toda a criança adora aprender coisas novas e como não é menos verdade que também gosta de brincar, por que não ensinála propondo brincadeiras saudáveis, gostosas e não competitivas. Mais ainda, 
motivando as crianças com dinâmicas e ludicidade, além de ensinar-Ihes tudo quanto consta em qualquer planejamento pedagógico. Dessa forma é possível provocar e trocar ideias e a liberação da criatividade, permitindo o desenvolvimento de sentimento de solidariedade e cooperação, exercícios de concentração, consciência sobre regras e sua aplicação no cotidiano e compreensão sobre a significação do perder e do ganhar.

Nesse sentido, percebe-se que brincadeiras e atividades práticas podem também abrigar intenções não apenas lúdicas e, desse modo, serem poderosos instrumentos de aprendizagem de valores e conceitos ambientais. É por esse motivo que a construção da aprendizagem significativa de uma criança e, sobretudo, a consciência que faz de valores para sua vida social e a excelência do educador, produzindo uma autêntica transformação, exige mais criatividade do que simplesmente passar uma informação ou distraí-los com atividades recreativas. Envolve procedimentos e práticas que reflitam a inclusão da alegria e os sentimentos de afetividade e amor recíproco.

\section{Sensibilização Ambiental}

Quando se busca resposta rápida para esse desafio, surge de imediato a convicção cartesiana de que somos "racionais". Não se duvida da filosofia, mas a observação despretensiosa do cotidiano revela que o ser humano é por vezes mais "emoção" do que "razão". Fácil constatar tudo isso ao se observar partidas nos estádios de futebol. Não é por acaso o que expressa a mãe que amamenta ou o pai que, orgulhoso, mostra as fotos de seu filho.

A emoção é talvez a mais autêntica expressão humana e poucas coisas falam de forma tão exuberante do modo de ser humano a ser senão a maneira como as emoções são colocadas nas falas e na justificativa de argumentos (DARWIN,2000). Dessa forma, se a emoção é tão marcante e significativa, por que as instituições de ensino não a ensinam na educação infantil, mostrando à criança de que maneira a legitimar?

Morin (2011) ensina, que para reconhecer a emoção é necessário compreendê-la e saber que é ser um humano e, por assim ser, ter momentos de raiva e de ternura, sentimentos de afeto e de vingança, instantes de tristeza e de alegria.

Cornell (2008) reflete sobre a aliança entre sensibilização ambiental e o educador, considerando importante que este partilhe seus sentimentos com as crianças. "Pois somente quando partilhamos nossos mais profundos pensamentos e sentimentos é que transmitimos aos outros - e os inspiramos o amor e o respeito pela Terra" (CORNELL, 2008, p. 27).

As crianças reagem a essas observações com muito mais espontaneidade do que reagiriam diante de explicações teóricas, ensina Cornell (2008). Ora, se as crianças aprendem o que vivenciam, vivenciar emoções e demonstrações de afeto dos educadores permitem que elas conheçam no cotidiano as emoções humanas. 
Quando se aborda a sensibilização ambiental, fala-se de um instrumento valioso para o desenvolvimento da educação ambiental. Esta auxilia no despertar de uma consciência, trazendo à tona a importância de se conservar, através de atividades dinâmicas e lúdicas que aproximem o público das realidades sobre as questões ambientais, sociais e culturais, contribuindo para a formação do sujeito ecológico e a promoção de um ambiente equilibrado para as atuais e futuras gerações (CARVALHO, 2011).

Como a educação ambiental, e grande parte da educação em geral, não consegue muitas vezes reconhecer o papel fundamental das emoções nos processos de aprendizagem, as atividades que tanto informam a mente quanto envolvem o coração surgem como uma combinação poderosa e eficaz.

Logo, verifica-se que a promoção de atividades que ajudem as crianças a se apaixonarem pelo planeta Terra faz-se essencial para a manutenção dos sistemas vivos. Jacques Cousteau ${ }^{10}$ concluiu que as pessoas protegem aquilo que amam, mas só amam aquilo que conhecem, nesse sentido, práticas educativas que permitam o conhecimento e intimidade com determinados ecossistemas é uma receita eficaz de preservação e conservação ambiental.

\section{Educação ambiental lúdica: Re significando a experiência de aprender}

Pensar em uma educação ambiental lúdica ${ }^{11}$ desde a educação infantil não é utopia. Durante a infância as aprendizagens estão bem conectadas com o meio natural. As crianças costumam gostar de animais, de plantas, da terra e se interessam pelos elementos da natureza. Emerge assim, a importância de desenvolver na educação infantil ações que busquem esse contato com o natural. Esses projetos podem ser incorporados a todas as áreas que atuam na educação infantil.

Segundo Vigotski (2007) o contexto social é importante para o brincar infantil. O brincar não pode ser separado das influências do mundo, pois não é apenas uma atividade interna da criança, mas está repleto de significação social. Nesse aspecto, Vigotski (2007, p.96) ressalta que "a criança ao nascer já está imersa em um contexto social, e a brincadeira torna-se importante justamente na apropriação do mundo, na internalização dos conceitos dos ambientes externos a ela".

Nesse contexto, favorecer brincadeiras na educação infantil não significa simplesmente deixar que as crianças brinquem livremente. $O$ educador induz a brincadeira com intervenções educativas, constituindo o papel de mediador. As

\footnotetext{
10 Disponivel em: https://www.youtube.com/watch?v=WuWsTYhV3AI\&feature=youtu.be

11 Lúdico: Que faz referência a jogos ou brinquedos: brincadeiras lúdicas. Divertido; que tem o divertimento acima de qualquer outro propósito. Feito através de jogos, brincadeiras, atividades criativas. (HOUAISS, 2009)

revista brasileira educação ambiental 
mediações se destacam pela intencionalidade das ações "unindo o útil ao agradável"12.

A mediação, não vem no sentido de impor ou obrigar o educando a uma determinada atividade, mas compõe-se em incentivar, mostrar e motivar as crianças. A mediação lúdica desabrocha em oportunidades para a criança participar de atividades conduzidas por um educador, possibilitando a criação, manifestação, interação e expressão infantil de diferentes formas, sem medo ou censura. Ou seja, constitui-se em experiências educativas (CARVALHO, 2005).

Jonh Dewey (1952, p. 10) definiu "educação como um processo de reconstrução e reorganização das experiências, percebendo mais atentamente os sentidos, e com isso nos habilitando a conduzir o curso das nossas experiências". Dessa forma, entende-se que a experiência educativa é algo que envolve a ação do aprendiz. Aquela capaz de envolver o educando com o objeto da aprendizagem, dando-Ihe significado. É o que Santos (2006) chama de aprendizagem significativa.

Ainda seguindo a lógica de Dewey (1952) a experiência educativa é aquela que permite à criança atribuir significados aos elementos. O significado é dado por fazer sentido interno. Dessa forma, o aprendiz internaliza conceitos e informações.

Essas abordagens interacionistas admitem que a aprendizagem depende da relação dinâmica entre o aprendiz e o meio, estabelecendo uma relação com o objeto a ser aprendido. Logo, uma educação ambiental lúdica deve considerar o conhecimento interpretativo do mundo. Possibilitar uma aprendizagem que estabeleça relações significativas. Para que a criança aprenda, é preciso que se envolva com o objeto de aprendizagem, de maneira que tenha poder sobre ele e desenvolva a capacidade de refletir, meditar e acrescentar sentido, permitindo um pensar que transforma, que constrói algo novo internamente em cada indivíduo.

\section{Considerações Finais}

A educação ambiental lúdica também se conecta com a educação ambiental vivencial. Esta fundamenta que vivências na natureza oferecem uma sensibilização e uma educação para mudanças de conduta necessárias para a construção de um ambiente saudável. Para tanto, a educação ambiental infantil requer vivências capazes de reestruturar as ações humanas, incitar a reflexão, estimular o autoconhecimento, provocar a consciência construindo, então, dia a dia, uma reeducação ambiental.

Infância e brincadeira caminham juntos. Na educação infantil brinca-se de muitas maneiras, com múltiplos aprendizados. A inserção de elementos da natureza nessas brincadeiras é bastante interessante. Durante o

12 Dito popular nordestino (autor desconhecido).

Revbea, São Paulo, V. 12, № 4: 60-75, 2017. 
desenvolvimento das crianças, ocorrem mudanças não apenas no conteúdo das brincadeiras, mas também no grau de interesses sociais, afetivos e cognitivos, além das brincadeiras que envolvem o corpo, jogos, espaço físico e natural, a brincadeira tem grande utilidade emocional, pois, nela, as crianças podem expressar conflitos, tristezas, alegrias e diversos outros sentimentos.

Que a ludicidade possa ser efetivada como um meio, e não um fim. Que seja utilizada para além de uma ferramenta pedagógica. O lúdico pode e deve criar oportunidades de construção da identidade dos sujeitos e intimidade com os elementos da natureza, fatores que ativam o protagonismo das crianças diante de conflitos ambientais a serem solucionados. Ensinar ludicamente é induzir à motivação e à diversão, pois tal atitude representa liberdade de expressão, a renovação e a criação do ser humano.

Os benefícios de um conhecimento construído em bases lúdicas, em especial durante a infância, aparecem tanto no aspecto físico, como no cognitivo. Fisicamente, favorece o crescimento, a expressão corporal, o desenvolvimento de habilidade motoras. Já do ponto cognitivo, contribui para a desinibição, produz excitação intelectual altamente estimulante, desenvolve habilidades de memória e eleva a estima. Além desses aspectos com a inserção da ludicidade em ações ou atividades educativas ambientais, as crianças aprendem a interagir com as pessoas, compartilhando, cedendo, recebendo e dispensando atenção aos seus pares, respeitando e sendo respeitadas. Compreender a importância da ludicidade para a educação ambiental infantil é colocar a criança como um ser social que é, de fato e de direito.

\section{Referências}

AGAMBEN, G. Infância e história: destruição da experiência e origem da história.Belo Horizonte: Editora UFMG/Humanitas, 2005.

ANTUNES, C. Interações, brincadeiras e valores na educação infantil. Petrópolis: Vozes, 2012.

AURÉLIO. B H. Dicionário Aurélio da Língua Portuguesa - Ed. Histórica 100 Anos. 5. ed. São Paulo: Positivo Editora, 2010.

BARCELOS, V. Educação Ambiental: sobre princípios, metodologias e atitudes. 4 ed. Petrópolis: Vozes, 2012.

BRASIL. Constituição. Constituição da República Federativa do Brasil. Brasília, DF, Senado, 1988. Disponível em:

BRASIL. Lei n. 9.795, de 27 de Abril de 1999. Institui a Política nacional de Educação Ambiental. Disponível em: $<$ http://www.planalto.gov.br/ccivil 03/Leis/L9795.htm> Acesso em: 18 Jan. 2016.

CARVALHO, A.M. et al. Brincar e educação: concepções e possibilidades. Psicologia em Estudo, Maringá, n.2, p.217-226, mai./ago. 2005.

revista brasileira educação ambiental 
CARVALHO, I.C.M, Educação ambiental e a formação do sujeito ecológico. 5 ed. São Paulo: Cortez, 2011.

CAPRA. F. Alfabetização Ecológica: a educação das crianças para um mundo sustentável. São Paulo: Cultrix, 2006.

CORNELL, J. Sharing nature with children. Dawn publications. 3. ed. São Paulo: Aquariana, 2008.

DARWIN, C. A expressão das emoções nos homens e nos animais. São Paulo: Companhia das letras. 2000.

DEWEY, J. Como pensamos. São Paulo: Companhia Nacional. 1952.

DEWEY, J. Democracia e Educação: capítulos essenciais. São Paulo: Ática, 2007.

DIAS, G.F. Educação Ambiental: princípios e práticas. São Paulo: Gaia, 2014. FREIRE. P.R.N. Pedagogia da autonomia: saberes necessários à pratica educativa. São Paulo: Paz e Terra, 2003.

GAGNEBIN, J. M. Infância e pensamento. In: GHIRALDELLI JÚNIOR, P. (org.). Infância, escola e modernidade. São Paulo: Cortez Editora, 1997. p. 83-100.

HORTON, M; FREIRE, P; BELL, B. O caminho se faz caminhando: conversas sobre educação e mudança social. São Paulo. Vozes; 2007

HOUAISS. A. Novo dicionário Houaiss da língua portuguesa. São Paulo, Moderna. 2009

MACHADO. P.A. L. Direito ambiental brasileiro. 22 ed. São Paulo. Malheiros, 2014.

MILARÉ, E. Direito do ambiente: a gestão ambiental em foco. 7. ed. São Paulo. Editora Revista dos Tribunais. 2013.

MORIN, E. A cabeça bem-feita: repensar a reforma, reformar o pensamento. 20. ed. Rio de Janeiro: Bertrand Brasil, 2012.

MORIN, E. Os sete saberes necessários à educação do futuro. 2. ed. São Paulo: Cortez, 2011.

PEREIRA, M. L. Inovação para o ensino de ciências naturais: método lúdico criativo experimental. João Pessoa: Editora Universitária/UFPB, 2003.

PIAGET, J. A formação do símbolo na criança: imitação, jogo, sonho, imagem e representação: Rio de Janeiro, LTC, 2012.

PIAGET, J. O nascimento da inteligência na criança. Trad. Alvaro Cabral. Rio de Janeiro: Zahar, 1995.

REIGOTA, M. Meio ambiente e representação social. 8. ed. São Paulo: Cortez, 2010. 
SANTOS, D.P. Psicopedagogia dos fantoches: jogo de imaginar, construir e narrar. 1. ed. São Paulo: Vetor, 2006.

SAUVÉ. L. Educação ambiental: possibilidades e limitações. Revista USP. V. 31, n. 2. 2005.

SATO, M. Educação para o ambiente amazônico. 245p., il. Tese (Doutorado) Universidade Federal de São Carlos, 1997. Disponível em: $<$ http://www.lapa.ufscar.br/pdf/tese doutorado michele sato.pdf> Acesso em: 21 jan 2016.

VIGOTSKI, L. S. Sobre a questão do multilinguismo na infância. Revista Teias do Programa de Pós-Graduação em Educação - ProPEd/UERJ, Rio de Janeiro, v. 6, n. 10-1, 2005.

VIGOTSKI, L. S. Sobre a questão da dinâmica do caráter infantil. Revista da Faculdade de Educação, Brasília, v. 12, n. 23, p. 279-291, jul./dez. 2006. Disponível em: <www.fe.unb.br/linhascriticas/linhascriticas/n23/sobre a.html> Acesso em: 02 abr. 2016 